\title{
Determination of ammonia removal from aqueous solution and volumetric mass transfer coefficient by microwave-assisted air stripping
}

\author{
O. N. $\operatorname{Ata}^{1} \cdot$ K. Aygun ${ }^{1} \cdot$ H. Okur' ${ }^{1}$ A. Kanca'
}

Received: 2 September 2015/Revised: 26 June 2016/Accepted: 23 July 2016/Published online: 10 August 2016

(C) Islamic Azad University (IAU) 2016

\begin{abstract}
In this study, the removal of ammonia from synthetically prepared ammonia solution at $\mathrm{pH} 11$ was investigated by using microwave radiation heating. Initially, conventional and microwave radiation heating were compared with respect to ammonia removal efficiency and overall volumetric mass transfer coefficient at five different temperatures. Overall volumetric mass transfer coefficient was calculated from the material balance for ammonia at unsteady-state condition. The effects of temperature, initial ammonia concentration, air flow rate, stirring speed, and microwave radiation power on both ammonia removal efficiency and overall volumetric mass transfer coefficient in liquid phase were also examined. The results of the experiments revealed that microwave-assisted air stripping allowed to the higher ammonia removal efficiency and overall volumetric mass transfer coefficient value compared to the conventional heating air stripping. Additionally, temperature and air flow rate were determined as the most substantial parameters affecting both ammonia removal efficiency and overall volumetric mass transfer coefficient value.
\end{abstract}

Keywords Ammonia removal $\cdot$ Microwave radiation - Air stripping Volumetric mass transfer coefficient

Editorial responsibility: T. Karak

Electronic supplementary material The online version of this article (doi:10.1007/s13762-016-1082-4) contains supplementary material, which is available to authorized users.

A. Kanca

akanca@atauni.edu.tr

1 Chemical Engineering Department, Engineering Faculty, Atatürk University, 25240 Erzurum, Turkey

\section{Introduction}

The presence of ammonia and its compounds in natural or industrial wastewaters is one of the major environmental problems. Industrial wastewaters, such as coke plant, tannery, textile, landfill leachate, and fertilizer wastewaters, contain ammonia in high concentration (Lin et al. 2009a; Yu et al. 1997; Tchobanoglous and Burton 1991). Since the presence of even small amounts of ammonia has serious negative effects on ecology and human health and it can be used as a raw material, the importance of researches on ammonia recovery increases. The recovery or/and removal of ammonia with low concentration and its compounds from wastewaters can be achieved by biological, physical, and chemical processes (Lin et al. 2009a, b) or by a combination of these processes, such as adsorption, chemical precipitation, membrane filtration, reverse osmosis, ion exchange, air stripping, breakpoint chlorination, and biological nitrification (Lin et al. 2009a). The recovery of industrial wastewaters by biological systems (Yu et al. 1997), chemical precipitation (Uludag-Demirer et al. 2005), supercritical water oxidation (Bermejo et al. 2008; Segond et al. 2002), and steam stripping (Ghose 2002; Yang et al. 1999) is not satisfied due to the following disadvantages: (1) Biological processes are usually difficult to treat ammonia containing wastewaters due to their toxic nature and the certain $C / N$ ratio requirement (Qian et al. 1994; Lin et al. 2009b), (2) chemical precipitation needs additional reagents leading to the formation of the new pollutants to the water sources (Uludag-Demirer et al. 2005), (3) supercritical water oxidation requires high temperatures and pressures (Bermejo et al. 2008), and (4) steam-stripping method uses a large stripping tower which consumes a large amount of energy, and ammonia concentration in effluent is often very high (Yang et al. 1999). 
Because of the drawbacks mentioned above paragraph, the microwave (MW) radiation technique has attracted much attention as an alternative approach. This cost-effective ammonia removal technique improves the rate of reaction by decreasing the reaction time and activation energy. This technique also provides high purification yield, easy control, and small equipment size. The thermal and non-thermal properties (i.e., superheating, polarization, dielectric properties, hot spot formation, nuclear spin rotation, and spin alignment) make MW technique more advantageous than traditional ones (Remya and Lin 2011).

MW radiation can be employed in the fields of organic and inorganic synthesis (Haswell and Howarth 1999; Zhang et al. 2007), polymerization processes (Correa et al. 1998), biological aspects (Banik et al. 2003), and extraction in analytical chemistry (Prevot et al. 2001). The removal of dyes, heavy metals, some organics, and ammonia from wastewater are also the special applications of the MW-assisted heating process (Quan et al. 2004; Yuan et al. 2006; Abramovitch et al. 1999; Gan 2000; Lin et al. 2009a, b). In 2009, Lin et al. reported in two studies that MW radiation heating is a promising way for ammonia removal from wastewater. Compared with the conventional heating with $60 \%$ ammonia removal efficiency, they obtained $\sim 95$ and $80 \%$ ammonia removal efficiency in laboratory-scale (Lin et al. 2009b) and pilot-scale (Lin et al. 2009a) experiments, respectively. In laboratory-scale experiments, Lin et al. tested the effect of $\mathrm{pH}$, aeration, radiation time, and initial ammonia concentration. The results of the study revealed that $\mathrm{MW}$ radiation time and $\mathrm{pH}$ are the more effective process parameters than the other. Ammonia removal efficiency increases with increasing $\mathrm{pH}$ and microwave radiation time, while aeration and initial ammonia concentration do not affect the process significantly (Lin et al. 2009b). After the bench-scale experiments, Lin et al. carried out the MW-assisted ammonia removal in the pilot-scale experiments (Lin et al. 2009a). They indicated that MW-assisted heating process can be applied effectively to remove ammonia in high concentration from the coke plant wastewater. Ambient temperature, waste solution flow rate, aeration condition, and initial ammonia concentrations were tested during the pilot-scale process. They obtained the consistent results with bench-scale experiments for the effect of aeration and initial ammonia concentration. Additionally, low flow rate of wastewater and high ambient temperature were found as the desired conditions for the higher ammonia removal efficiency (Lin et al. 2009a). These two fundamental studies motivated us for the further investigation of MW-assisted ammonia removal from wastewater. In order to contribute to this process, we focused on the systematic analyses of process parameters. In addition to initial ammonia concentration, we defined the new system parameters for the MW-assisted air stripping process as MW furnace temperature, air flow rate, stirring speed, and MW radiation power. Ammonia removal efficiency and overall mass transfer coefficient were selected as dependent variables to test the system parameters.

In the light of the given information, two main aims of the present study are (1) to compare the ammonia removal performance and overall volumetric mass transfer coefficients $\left(K_{\mathrm{L}} a\right)$ of microwave-assisted and conventional heating air stripping processes at five different temperatures $\left(20,30,40,50\right.$, and $\left.60^{\circ} \mathrm{C}\right)$ in liquid phase and (2) to determine the effect of temperature, initial ammonia concentration, air flow rate, stirring speed, and microwave radiation power on both ammonia removal efficiency and overall volumetric mass transfer coefficient. At this point, the disappearance of ammonia by microwave-assisted air stripping from synthetically prepared ammonia solution at $\mathrm{pH} 11$ was used in order to determine the overall volumetric mass transfer coefficients in liquid phase by means of mathematical modeling of ammonia removal.

This study was carried out in 2014 at Chemical Engineering Department, Atatürk University, in Turkey.

\section{Materials and methods}

\section{Reagents}

Ammonium chloride $\left(\mathrm{NH}_{4} \mathrm{CI}\right)$ and deionized water were used to prepare the synthetic ammonia solution, and $\mathrm{NaOH}$ was employed to adjust $\mathrm{pH}$ value of the final solution at 11 . $\mathrm{NH}_{4} \mathrm{CI}$ and $\mathrm{NaOH}$ reagents used in the experiments were obtained from Fluka Co. To test the effect of initial ammonia concentration on the ammonia removal yield and volumetric mass transfer coefficient $\left(K_{\mathrm{L}} a\right), 500 \mathrm{~mL}$ ammonia solution with different initial concentrations was prepared as a representative wastewater containing ammonia.

\section{Description of process and equipment}

Two dependent variables, namely ammonia removal efficiency and volumetric mass transfer coefficient $\left(K_{\mathrm{L}} a\right)$, were selected as the determining parameters for the testing of ammonia removal from the industrial wastewater. The influences of temperature, initial ammonia concentration, air flow rate, stirring rate, and microwave radiation power on ammonia removal efficiency and $K_{\mathrm{L}} a$ were examined by microwave-assisted air stripping systems. Since only temperature effect on ammonia removal and $K_{\mathrm{L}} a$ was determined for both heating furnaces, the conventional and MW heating were compared in terms of the ammonia removal 
efficiency and $K_{\mathrm{L}} a$ values. Other parameters were tested by using only MW radiation heating.

During the experiments, $\mathrm{pH}$ values of the ammonia solutions $(\mathrm{pH}=11)$ were followed by pMX 3000/ION pH meter. After the solution was prepared, it was placed into the $750 \mathrm{~mL}$ glass reactor equipped with gas inlet and outlet and a mechanical stirrer. The details of the experimental design are given in Fig. 1. Since the heating process was conducted by using two heating equipments, conventional and microwave radiation, two ovens are demonstrated in the figure. During the conventional heating process, temperature of ammonia solution was kept constant within $\pm 0.1{ }^{\circ} \mathrm{C}$ of the desired temperature value by thermostat. On the other hand, the desired temperature was set by the apparatus operated in the automatic mode of the MW furnace. During the MW operation, temperature rises above the desired value, microwave energy transmission was automatically cut off and fell below the set value, and very little microwave energy was sent again. A laboratory-type microwave (MW) reactor with a frequency of $2.475 \mathrm{GHz}$ and a maximum output power of $1 \mathrm{~kW}$, consisting of five sections, was used in this study. The first section of the apparatus includes the generator with manual and automatic controls. The second section consists of a PHILIPS microwave circulator with a frequency of $2.475 \mathrm{GHz}$. The third section is an R26 standard rectangular waveguide. Three manually adjustable stub tuners (which are) placed in the waveguide section and the tuning plunger of the applicator, are used to maximize the microwave absorption by minimizing the reflected power. The fourth section consists of an MUFGGE DIR COUPLER MM 1002C model coupler measuring the reflected power. The fifth part is the cavity section. A cylindrical Pyrex reactor was placed in this section at the position of the highest electric field, with an internal volume of $750 \mathrm{~mL}$, an internal diameter of $89 \mathrm{~mm}$. For temperature measurements, an optical fiber connected to a transducer (PT-100) was used.

\section{Process parameters}

Five process parameters, temperature, initial ammonia concentration, air flow rate, stirring rate, and the power of MW radiation, were tested. All experiments were conducted at $\mathrm{pH}$ 11. Among them, temperature was employed to compare two heating processes, which are conventional heating and MW radiation. The details of the parameters examined during the ammonia removal tests are given in Table 1 for the comparison of MW and conventional treatments and Table 2 for the MW-assisted ammonia removal process.

Returned power display

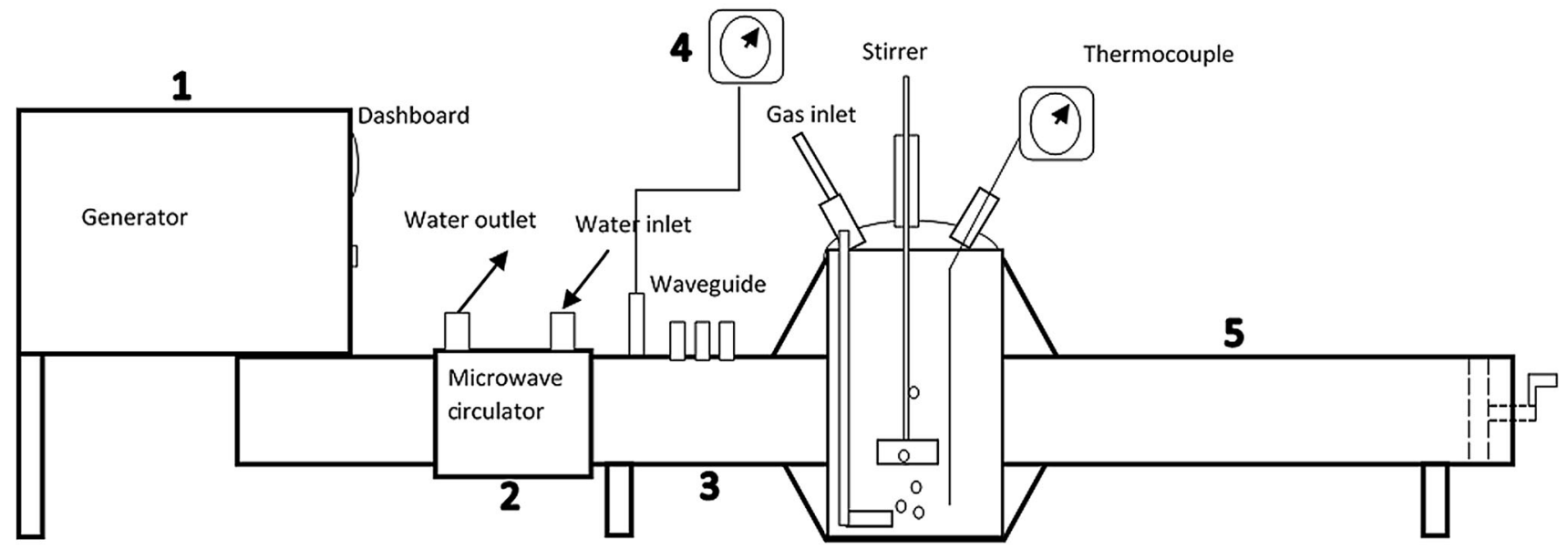

Fig. 1 Schematic representation of the experimental ammonia removal setup

Table 1 Process parameters used to compare the conventional and MW treatment

\begin{tabular}{lllll}
\hline $\begin{array}{l}\text { Process parameters } \\
\text { tested }\end{array}$ & $\begin{array}{l}\text { Initial ammonia } \\
\text { concentration }(\mathrm{ppm})\end{array}$ & Temperature $\left({ }^{\circ} \mathrm{C}\right)$ & $\begin{array}{l}\text { Air flow rate } \\
(\mathrm{L} / \mathrm{min})\end{array}$ & $\begin{array}{l}\text { Stirring rate } \\
(\mathrm{rpm})\end{array}$ \\
\hline $\begin{array}{c}\text { Conventional heating } \\
\text { Temperature }\left({ }^{\circ} \mathrm{C}\right)\end{array}$ & 1000 & $20,30,40,50$, and 60 & 7.5 & $\begin{array}{l}\text { Power of MW } \\
(\mathrm{W})\end{array}$ \\
$\begin{array}{c}\text { Microwave heating } \\
\text { Temperature }\left({ }^{\circ} \mathrm{C}\right)\end{array}$ & 1000 & $20,30,40,50$, and 60 & 7.5 & 500 \\
\hline
\end{tabular}


Table 2 Process parameters tested during the MW-assisted ammonia removal process

\begin{tabular}{|c|c|c|c|c|c|}
\hline Process parameters tested & $\begin{array}{l}\text { Initial ammonia } \\
\text { concentration (ppm) }\end{array}$ & $\begin{array}{l}\text { Temperature } \\
\left({ }^{\circ} \mathrm{C}\right)\end{array}$ & $\begin{array}{l}\text { Air flow rate } \\
(\mathrm{L} / \mathrm{min})\end{array}$ & $\begin{array}{l}\text { Stirring rate } \\
(\mathrm{rpm})\end{array}$ & $\begin{array}{l}\text { Power of MW } \\
\text { (W) }\end{array}$ \\
\hline Temperature $\left({ }^{\circ} \mathrm{C}\right)$ & 1000 & $20,30,40,50$, and 60 & 7.5 & 500 & 450 \\
\hline $\begin{array}{l}\text { Initial ammonia } \\
\text { concentration (ppm) }\end{array}$ & $\begin{array}{l}500,1000,1500, \\
2000, \text { and } 2500\end{array}$ & 20 & 7.5 & 500 & 450 \\
\hline Air flow rate $(\mathrm{L} / \mathrm{min})$ & 1000 & 20 & $\begin{array}{l}1.5,3.0,4.5 \\
6.0, \text { and } 7.5\end{array}$ & 500 & 450 \\
\hline Stirring rate (rpm) & 1000 & 20 & 7.5 & $\begin{array}{l}200,300,400, \\
500, \text { and } 600\end{array}$ & 450 \\
\hline Power of MW (W) & 1000 & 20 & 7.5 & 500 & $150,300,450$, and 550 \\
\hline
\end{tabular}

\section{Analysis}

The final ammonia concentration in liquid phase at any time was determined by ammonia analysis through Thermo Orion $\mathrm{A}^{+}$Ion-meter and Spectrophotometer (Analytic Jena 1100). The efficiency of ammonia removal is calculated according to Eq. 1.

$(\%)$ Efficiency $=\frac{C_{\mathrm{Lo}}-C_{\mathrm{Lt}}}{C_{\mathrm{Lo}}}$

where $C_{\mathrm{Lt}}$ is ammonia concentration in liquid phase at any time $(\mathrm{mg} / \mathrm{L})$, and $C_{\mathrm{Lo}}$ is the initial ammonia concentration in liquid phase $(\mathrm{mg} / \mathrm{L}$ or $\mathrm{ppm})$.

\section{Methodology for the volumetric mass transfer coefficient}

The overall ammonia balance over the reactor is given by Eq. 2 :

$Q_{\mathrm{G}} C_{\mathrm{Gin}}-Q_{\mathrm{G}} C_{\mathrm{Gout}}=V_{\mathrm{L}} \frac{\mathrm{d} C_{\mathrm{L}}}{\mathrm{d} t}+\varepsilon_{\mathrm{G}} V_{\mathrm{L}} \frac{\mathrm{d} C_{\mathrm{G}}}{\mathrm{d} t}$

where $Q_{\mathrm{G}}$ is the volumetric flow rate of air $(\mathrm{L} / \mathrm{min}), C_{\mathrm{Gin}}$ and $C_{\text {Gout }}$ are ammonia concentrations in the air inlet and outlet of reactor $(\mathrm{mg} / \mathrm{L})$, respectively, $V_{\mathrm{L}}$ is the liquid volume $(\mathrm{L})$, $C_{\mathrm{L}}$ is the ammonia concentration in liquid phase $(\mathrm{mg} / \mathrm{L})$, and $\varepsilon_{\mathrm{G}}$, dimensionless variable, is the gas holdup or the volume fraction of the gas bubbles entrained in the liquid.

When accumulation term of ammonia in the gas phase $\left(\varepsilon_{\mathrm{G}} V_{\mathrm{L}} \frac{\mathrm{d} C_{\mathrm{G}}}{\mathrm{d} t}\right)$ and $C_{\mathrm{Gin}}$ is zero, Eq. 2 is rearranged in Eq. 3:

$-Q_{\mathrm{G}} C_{\mathrm{Gout}}=V_{\mathrm{L}} \frac{\mathrm{d} C_{\mathrm{L}}}{\mathrm{d} t}$

For a dilute system, differential material balance for the ammonia over a differential height $\mathrm{d} z$ of the reactor gives Eq. 4:

$$
\begin{aligned}
& Q_{\mathrm{G}} C_{\mathrm{G}}-Q_{\mathrm{G}}\left(C_{\mathrm{G}}+\mathrm{d} C_{\mathrm{G}}\right)+K_{\mathrm{L}} a S\left(C_{\mathrm{L}}-C_{\mathrm{L}}^{*}\right) \mathrm{d} z \\
& \quad=\varepsilon_{\mathrm{G}} S \mathrm{~d} z \frac{\mathrm{d} C_{\mathrm{G}}}{\mathrm{d} t}
\end{aligned}
$$

where $K_{\mathrm{L}} a$ is the overall volumetric mass transfer coefficient in liquid phase $\left(\mathrm{h}^{-1}\right), \mathrm{S}$ is the cross-sectional area of the reactor $\left(\mathrm{m}^{2}\right), \mathrm{d} z$ is the differential height $(\mathrm{m})$, a is the specific interfacial area of bubbles per unit volume of the gas-liquid mixture $\left(\mathrm{m}^{2} / \mathrm{m}^{3}\right)$, and $C_{\mathrm{L}}^{*}$ is the ammonia concentration in the liquid phase in equilibrium with the gas bubbles $(\mathrm{mg} / \mathrm{L})$. The equilibrium between the gas and liquid phases is expressed by Henry's law (Eq. 5)

$C_{\mathrm{L}}^{*}=\frac{C_{\mathrm{G}}}{K_{\mathrm{H}}}$

where $K_{\mathrm{H}}$ is Henry's law constant (dimensionless). Noting that the accumulation term in Eq. 4 is zero and thus substitution of Eq. 5 into Eq. 4 yields Eq. 6

$\int_{C_{\text {Gin }}}^{G_{\text {Gout }}} \frac{\mathrm{d} C_{\mathrm{G}}}{C_{\mathrm{L}}-C_{\mathrm{G}} / K_{\mathrm{H}}}=\int_{0}^{\mathrm{Le}} \frac{K_{\mathrm{L}} a S}{Q_{\mathrm{G}}} \mathrm{d} z \Rightarrow C_{\mathrm{Gout}}=C_{\mathrm{L}} K_{\mathrm{H}}\left[1-\mathrm{e}^{\frac{K_{\mathrm{L}} a S \mathrm{LL}}{Q_{\mathrm{G}} K_{\mathrm{H}}}}\right]$

where Le is the effective height of gas-liquid mixture (m). Substitution of Eq. 6 into Eq. 3 yields Eq. 7

$-\ln \frac{C_{\mathrm{Lt}}}{C_{\mathrm{Lo}}}=\frac{K_{\mathrm{H}} Q_{\mathrm{G}}}{V_{\mathrm{L}}}\left[1-\mathrm{e}^{-\left(\frac{K_{\mathrm{L}} a \mathrm{LLe}}{Q_{\mathrm{G}} K_{\mathrm{H}}}\right)}\right] t$

where $C_{\mathrm{Lt}}$ is the ammonia concentration in the liquid phase at any time $(\mathrm{mg} / \mathrm{L})$, and $C_{\mathrm{Lo}}$ is the initial ammonia concentration in the liquid phase $(\mathrm{mg} / \mathrm{L}$ or $\mathrm{ppm})$. As a result, Eq. 7 finally obtained can be used to predict the rate of ammonia removal by air stripping from the solution containing ammonia in a reactor. The slope of $\left[-\ln \left(C_{\mathrm{Lt}} / C_{\mathrm{Lo}}\right)\right]$ versus time graph gives the volumetric mass transfer coefficient $\left(K_{\mathrm{L}} a\right)$ of ammonia in liquid phase.

\section{Results and discussion}

\section{Comparison of conventional and MW heating systems depending on temperature}

In order to determine the influence of temperature on the efficiency of ammonia removal and volumetric mass 

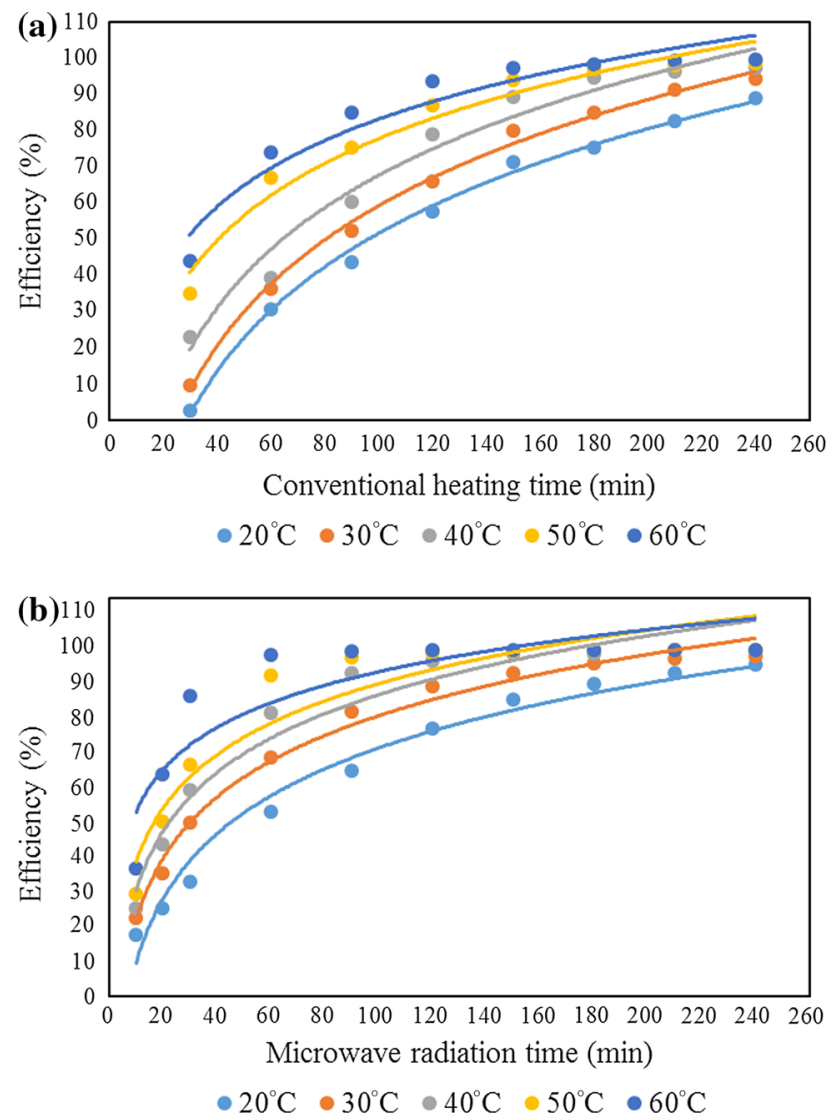

Fig. 2 Temperature effect on ammonia removal efficiency with respect to heating time by using (a) conventional heating and (b) MW heating

transfer coefficient $\left(K_{\mathrm{L}} a\right)$, the experiments were performed by using the conventional and microwave heating furnaces at temperatures between 20 and $60{ }^{\circ} \mathrm{C}$. As shown in Table 1, initial ammonia concentration was $1000 \mathrm{mg} / \mathrm{L}$ (ppm) and solution $\mathrm{pH}$ was 11 . Air flow rate and stirring speed were maintained as $7.5 \mathrm{~L} / \mathrm{min}$ and $500 \mathrm{rpm}$, respectively. Microwave output power of $450 \mathrm{~W}$ was employed in the MW heating experiments.

The effects of temperature on the efficiency of ammonia removal and $K_{\mathrm{L}} a$ are shown in Figs. 2 and 3, respectively. As seen in these figures, the common observation for both heating processes is that the rising temperature has an extremely important effect on both the efficiency of ammonia removal and $K_{\mathrm{L}} a$.

When the conventional heating was employed, $K_{\mathrm{L}-}$ $a$ value was found as nearly $2.5 \times$ higher at $60{ }^{\circ} \mathrm{C}$ than at $20{ }^{\circ} \mathrm{C}$. On the other hand, $K_{\mathrm{L}} a$ increased by almost 4.3 -fold when the temperature is increased from 20 to $60{ }^{\circ} \mathrm{C}$ in the presence of MW radiation.

Although it can be observed from Figs. 2 and 3 that the efficiency of ammonia removal and $K_{\mathrm{L}} a$ increases with increasing temperature, microwave radiation heating provided the better results compared to the conventional heating experiments. This can be explained that microwave
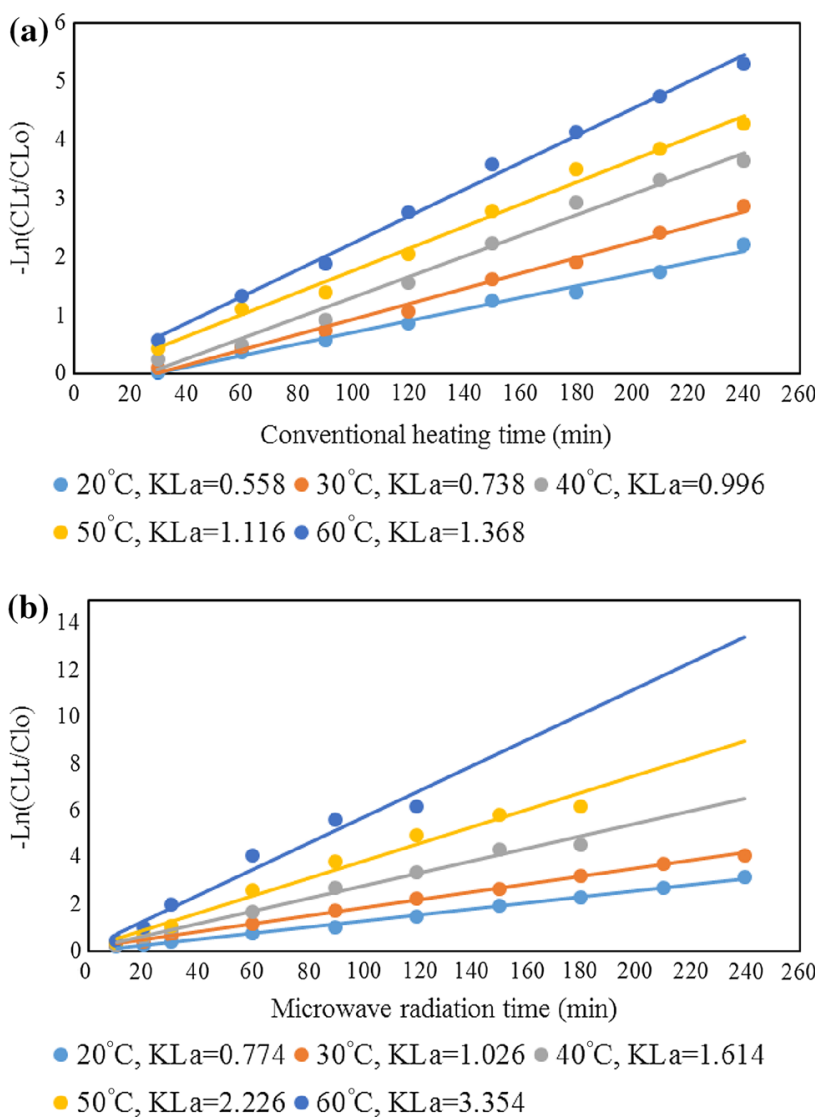

Fig. 3 Effect of temperature on $K_{\mathrm{L}} a\left(\mathrm{~h}^{-1}\right)$ by using (a) conventional heating and (b) MW heating

radiation heating is fast and the resulting molecular-level heating leads to homogeneous and quick thermal decomposition. In addition, the particular non-thermal effect enhances the ammonia removal, efficiently (Venkatesh and Raghavan 2004). Both effects allow to the high efficiency of ammonia removal.

The increasing temperature enhances the molecular diffusion coefficient of ammonia in both the liquid film and gas film and also promotes the liquid phase viscosity and surface tension and the liquid-gas distribution ratio of ammonia. On the contrary, the increasing temperature has an extremely important effect on the removal of ammonia from water because of the decreasing dissolution. Thus, the effect of the temperature mentioned before causes to increase in the rate of mass transfer.

\section{Evaluation of operating parameters during the microwave-assisted ammonia removal}

Since ammonia was removed more efficiently in the presence of MW heating equipment than conventional one, the effects of other parameters were examined by using only MW radiation. The process parameters are presented in Table 2. 


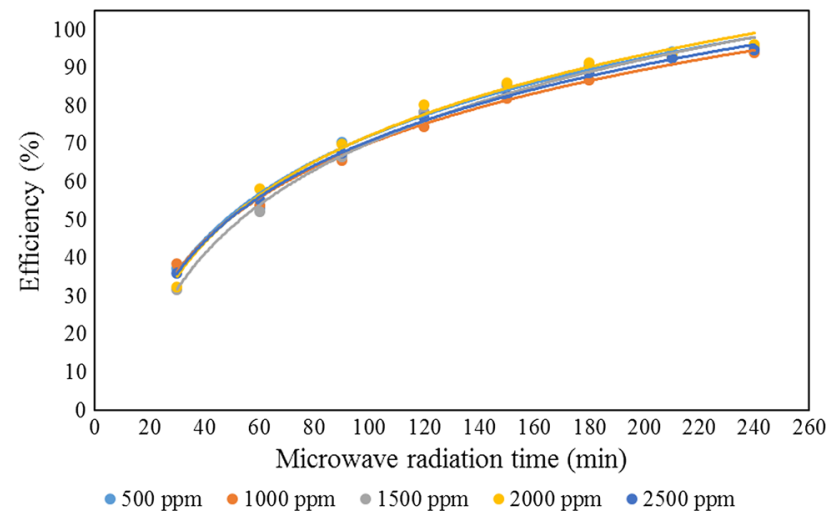

Fig. 4 Effect of initial ammonia concentration on the efficiency of ammonia removal

\section{Effect of initial ammonia concentration}

The effect of the initial ammonia concentration on ammonia removal was tested at $20{ }^{\circ} \mathrm{C}$ and at $450 \mathrm{~W} \mathrm{MW}$ power. Air flow rate and stirring speed were $7.5 \mathrm{~L} / \mathrm{min}$ and $500 \mathrm{rpm}$, respectively (Table 2). Figure 4 shows how initial ammonia concentration affects the ammonia removal efficiency. As seen from the figure, maximum ammonia removal can be achieved by the same MW radiation time for the different ammonia concentrations between 500 and $2500 \mathrm{ppm}$. As a result, ammonia removal efficiency does not change with the increasing initial ammonia concentration.

Figure 5 indicates the influence of the initial ammonia concentration on the overall volumetric mass transfer coefficient $\left(K_{\mathrm{L}} a\right)$. The $K_{\mathrm{L}} a$ values for each level of parameters were obtained from Eq. 7 by plotting $\left[-\ln \left(C_{\mathrm{Lt}} /\right.\right.$ $\left.C_{\mathrm{Lo}}\right)$ ] versus stripping time (min) and making a linear regression between them. The results revealed that $K_{\mathrm{L}-}$ $a$ was also not affected by the initial ammonia concentration, significantly. For example, while initial ammonia concentration varied from 500 to $2500 \mathrm{ppm}, K_{\mathrm{L}} a$ values (Fig. 5) varied from 0.792 to $0.720 \mathrm{~h}^{-1}$.

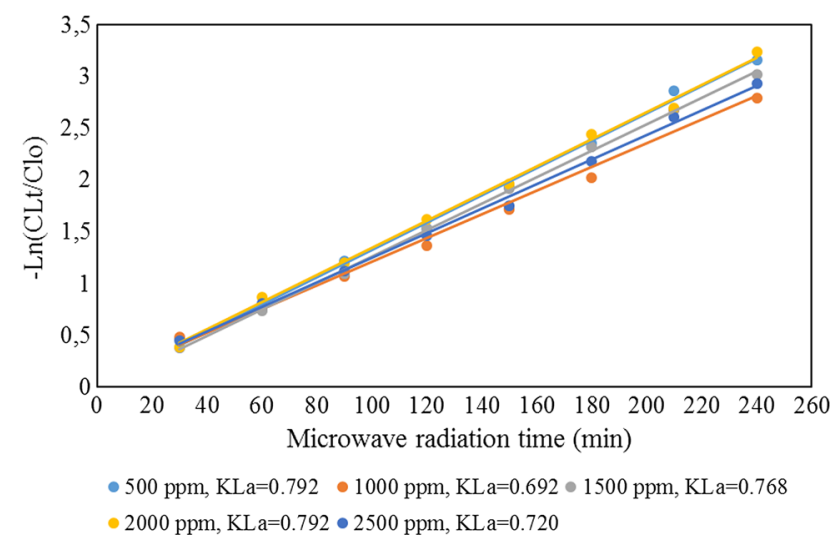

Fig. 5 Effect of initial ammonia concentration on $K_{\mathrm{L}} a\left(\mathrm{~h}^{-1}\right)$
Effect of the air flow rate

Gas dispersion plays a critical role in determining the performance of the gas-liquid system. Generally, the uniform dispersion of small bubbles is required in order both to keep a maximum level of interfacial area and to enhance the transport phenomena. The influences of the gas flow rate on ammonia removal efficiency and $K_{\mathrm{L}} a$ are shown in Figs. 6 and 7, respectively. System parameters during the testing of air flow rate are presented in Table 2. As shown in Fig. 6, time which is required for the well mixing of ammonia in the reactor decreases with increasing air flow rate. For example, at the end of $240 \mathrm{~min}$, nearly $55 \%$ ammonia removal efficiency was obtained during $1.5 \mathrm{~L} /$ min air flow rate, while efficiency was recorded as approximately $95 \%$ when air flow rate is $7.5 \mathrm{~L} / \mathrm{min}$.

Similar to ammonia removal efficiency, $K_{\mathrm{L}} a$ value increased with the increasing air flow rate at given experimental conditions. While the air flow rate changes from 1.5 to $7.5 \mathrm{~L} / \mathrm{min}, K_{\mathrm{L}} a$ values presented in Fig. 7 vary from 0.192 to $0.786 \mathrm{~h}^{-1}$. Increase in gas flow rate results in

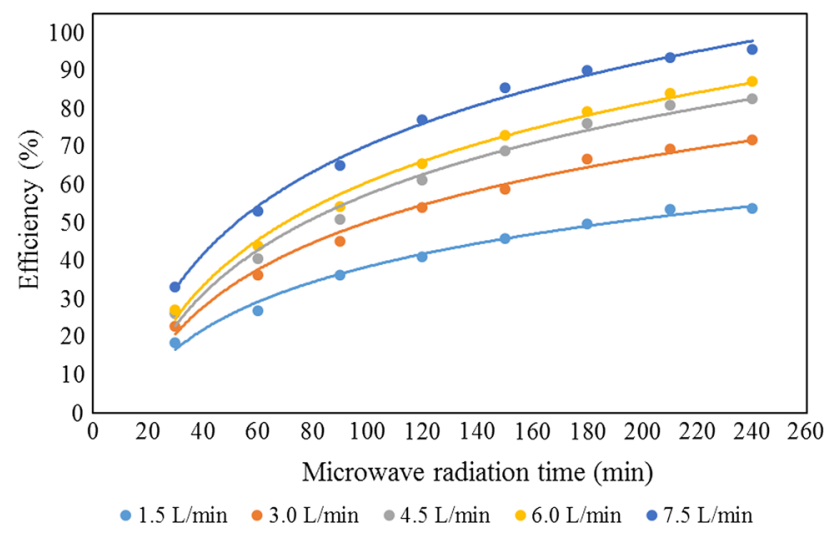

Fig. 6 Effect of air flow rate on ammonia removal efficiency by microwave heating

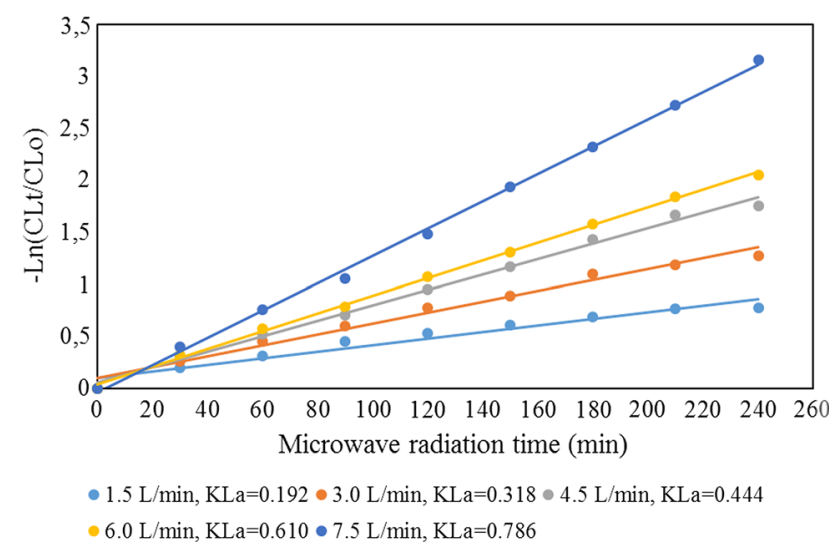

Fig. 7 Effect of air flow rate on $K_{\mathrm{L}} a\left(\mathrm{~h}^{-1}\right)$ 
decrease in size of gas bubbles dispersed in the liquid phase (Prasad and Ramanujam 1995; Jain et al. 1990). This leads to increase in the gas entrainment and gas-liquid interfacial area. As a result, ammonia removal efficiency increases. Conversely, the overall mass transfer resistance for ammonia removal mainly forms resistance on the gas film side because of high solubility of ammonia in water. Therefore, the overall mass transfer resistance can be reduced by increasing the air flow rate.

\section{Effect of stirring speed}

Stirring speed was tested for five different rates $(200,300$, 400,500 , and $600 \mathrm{rpm}$ ) at $20{ }^{\circ} \mathrm{C}$. Figures 8 and 9 indicate the effects of the stirring speed on the efficiency of ammonia removal and $K_{\mathrm{L}} a$, respectively. It is observed from these figures that the stirring speed has very little effect on the efficiency of ammonia removal and $K_{\mathrm{L}} a$. It is well known that stirring speed allows the uniform dispersion of gas bubbles in the liquid phase. However, since air was fed to the reactor with a distributor, the uniform dispersion of gas bubbles was achieved even if stirring speed

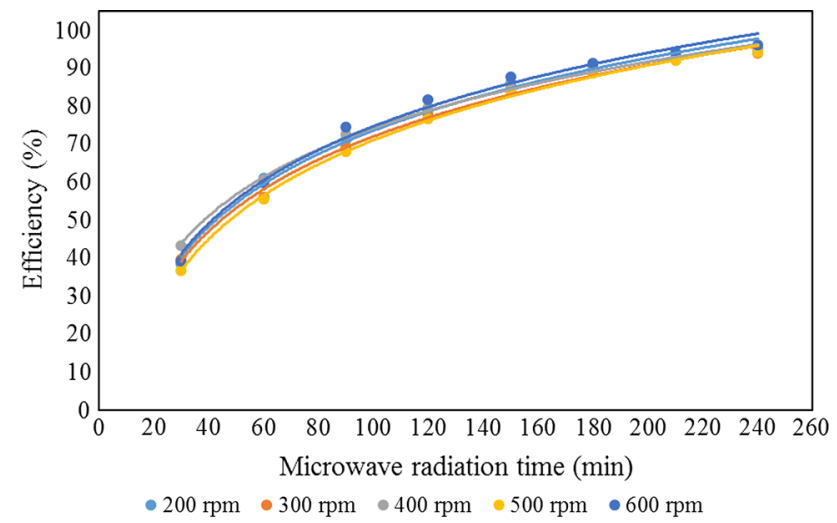

Fig. 8 Effect of stirring speed on the efficiency of ammonia removal

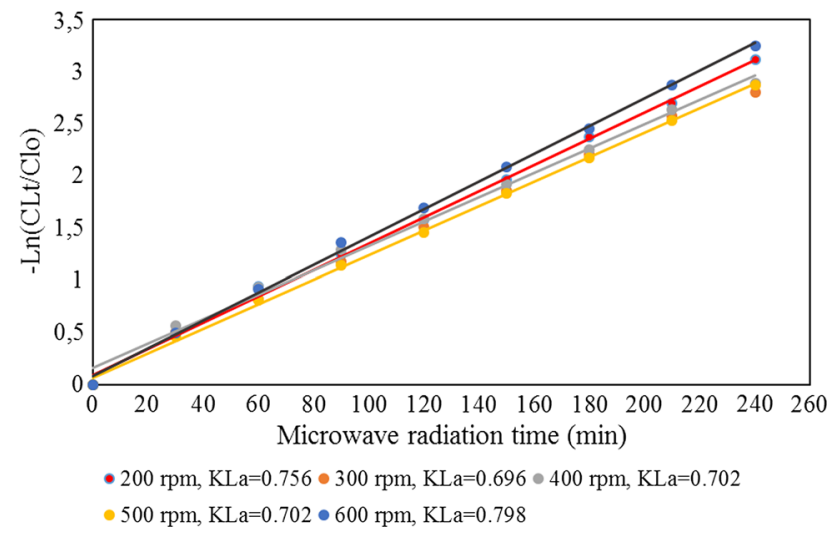

Fig. 9 Effect of stirring speed on $K_{\mathrm{L}} a\left(\mathrm{~h}^{-1}\right)$ was at the lowest stage. This result can be interpreted that there is no stirring speed effect on the removal efficiency and $K_{\mathrm{L}} a$.

\section{Effect of microwave output power}

Power is a measure of the amount of energy carried by microwaves. During operation, the system temperature is automatically kept constant. Microwave energy is sent to the system to maintain a specific temperature. If this energy is high, a short period of time is necessary for the energy transfer to the system. In order to determine the effect of MW output power, $150,300,450$, and $550 \mathrm{~W}$ powers were applied at $20^{\circ} \mathrm{C}$. The effects of the output power of microwave on the efficiency of ammonia removal (Fig. 10) and $K_{\mathrm{L}} a$ (Fig. 11) revealed that the output power of the microwave has little effect on the efficiency of ammonia removal and $K_{\mathrm{L}} a$. The system is exposed to microwave currents for longer time when the microwave power is running low. However, the same amount of energy is released for a relatively long period of time and it is transferred to the system as a low-density energy.

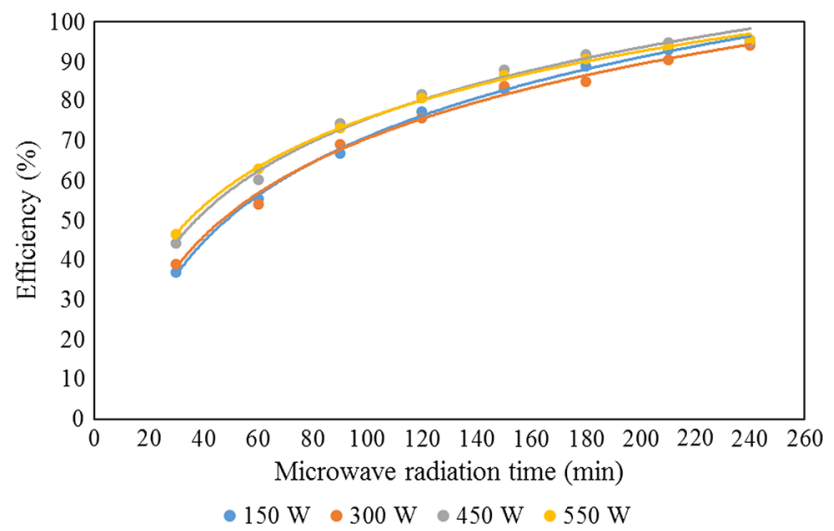

Fig. 10 Effect of microwave output power on ammonia removal efficiency

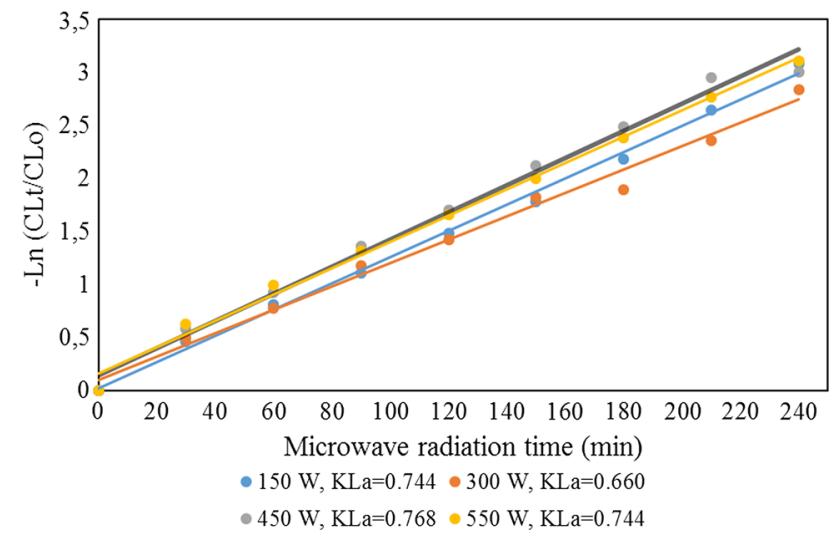

Fig. 11 Effect of microwave output power on $K_{\mathrm{L}} a\left(\mathrm{~h}^{-1}\right)$ 


\section{Conclusion}

The results of the present study revealed that ammonia removal performance of microwave-assisted air stripping is 20-25\% higher than that of conventional heating air stripping. Since the heating process with MW radiation allows high mass transfer rate of ammonia, the utilization of MW radiation can be considered as an alternative way to accomplish the ammonia removal from toxic industrial wastewater. Furthermore, among the process parameters, temperature and air flow rate have a very substantial effect, while initial ammonia concentration, the stirring speed, and the microwave output power have little effect on the ammonia removal efficiency and $K_{\mathrm{L}} a$.

Acknowledgments The authors are grateful for Scientific Research Projects Foundation for financial support (BAP-2012-104) and for Chemical Engineering Department Laboratory of Atatürk University management and staff for their support and service.

\section{Nomenclature}

$Q_{\mathrm{G}} \quad$ Air volumetric flow rate $(\mathrm{L} / \mathrm{min})$

$C_{\mathrm{Gin}} \quad$ Ammonia concentration in the air inlet of the reactor $(\mathrm{mg} / \mathrm{L})$

$C_{\text {Gout }} \quad$ Ammonia concentration in the air outlet of the reactor $(\mathrm{mg} / \mathrm{L})$

$V_{\mathrm{L}} \quad$ The liquid volume (L)

$C_{\mathrm{L}} \quad$ Ammonia concentration in the liquid phase $(\mathrm{mg} / \mathrm{L})$

$\varepsilon_{\mathrm{G}} \quad$ Gas holdup or the volume fraction of the gas bubbles that are entrained in the liquid (dimensionless)

$K_{\mathrm{L}} a \quad$ The overall volumetric mass transfer coefficient based on the liquid phase $\left(\mathrm{h}^{-1}\right)$

$S$

$\mathrm{d} z \quad$ The differential height $(\mathrm{m})$

$a \quad$ The specific interfacial area of bubbles per unit volume of the gas-liquid mixture $\left(\mathrm{m}^{2} /\right.$ $\mathrm{m}^{3}$ )

$C_{\mathrm{L}}^{*} \quad$ Ammonia concentration in the liquid phase in equilibrium with the gas bubbles $(\mathrm{mg} / \mathrm{L})$

$K_{\mathrm{H}} \quad$ Henry's law constant (dimensionless)

Le The effective height of the gas-liquid mixture (m)

$C_{\mathrm{Lt}} \quad$ Ammonia concentration in the liquid phase at any time $(\mathrm{mg} / \mathrm{L})$

$C_{\mathrm{Lo}} \quad$ Initial ammonia concentration in the liquid phase $(\mathrm{mg} / \mathrm{L})$

\section{References}

Abramovitch RA, Bangzhou H, Abramovitch DA, Jiangao S (1999) In situ decomposition of PAHs in soil and desorption of organic solvents using microwave energy. Chemosphere 39:81-87
Banık S, Bandyopadhyay S, Ganguly S (2003) Bioeffects of microwave-a brief review. Bioresour Technol 87:155-159

Bermejo MD, Cantero F, Cocero MJ (2008) Supercritical water oxidation of feeds with high ammonia concentrations: pilot plant experimental results and modeling. Chem Eng J 137:542-549

Correa R, Gonzalez G, Dougar V (1998) Emulsion polymerization in a microwave reactor. Polymer 39:1471-1474

Gan Q (2000) A case study of microwave processing of metal hydroxide sediment sludge from printed circuit board manufacturing wash water. Waste Manag 20:695-701

Ghose MK (2002) Complete physico-chemical treatment for coke plant effluents. Water Res 36:1127-1134

Haswell SJ, Howarth N (1999) Perturbation of a solid phase separation process by a non-thermal microwave effect. Anal Chim Acta 387:113-120

Jain DK, Patwarı AN, Khan AA, Rao MB (1990) Liquid circulation characteristics in jet loop reactors. Can J Chem Eng 68:1047-1051

Lin L, Chen J, Xu Z, Yuan S, Cao M, Liu H, Lu X (2009a) Removal of ammonia nitrogen in wastewater by microwave radiation: a pilot-scale study. J Hazard Mater 168:862-867

Lin L, Yuan S, Chen J, Xu Z, Lu X (2009b) Removal of ammonia nitrogen in wastewater by microwave radiation. J Hazard Mater 161:1063-1068

Prasad KY, Ramanujam TK (1995) Gas holdup and overall volumetric mass transfer coefficient in a modified reversed flow jet loop reactor. Can J Chem Eng 73:190-195

Prevot AB, Gulmını M, Zelano V, Pramauro E (2001) Microwaveassisted extraction of polycyclic aromatic hydrocarbons from marine sediments using nonionic surfactant solutions. Anal Chem 73:3790-3795

Qian Y, Wen Y, Zhang H (1994) Efficacy of pre-treatment methods in the activated sludge removal of refractory compounds in cokeplant wastewater. Water Res 28:701-707

Quan X, Liu X, Bo L, Chen S, Zhao Y, Cu1 X (2004) Regeneration of acid orange 7-exhausted granular activated carbons with microwave irradiation. Water Res 38:4484-4490

Remya N, Lin J-G (2011) Current status of microwave application in wastewater treatment-a review. Chem Eng J 166:797-813

Segond N, Matsumura Y, Yamamoto K (2002) Determination of ammonia oxidation rate in sub- and supercritical water. Ind Eng Chem Res 41:6020-6027

Tchobanoglous G, Burton FL (1991) Wastewater engineering. Management 7:1-4

Uludag-Demırer S, Demirer GN, Chen S (2005) Ammonia removal from anaerobically digested dairy manure by struvite precipitation. Process Biochem 40:3667-3674

Venkatesh MS, Raghavan GSV (2004) An overview of microwave processing and dielectric properties of agri-food materials. Biosyst Eng 88:1-18

Yang M, Uesug1 K, Myoga H (1999) Ammonia removal in bubble column by ozonation in the presence of bromide. Water Res 33:1911-1917

Yu H, Gu G, Song L (1997) Posttreatment of effluent from coke-plant wastewater treatment system in sequencing batch reactors. J Environ Eng 123:305-308

Yuan S, Tian M, Lu X (2006) Microwave remediation of soil contaminated with hexachlorobenzene. J Hazard Mater 137:878-885

Zhang YM, Wang P, Han N, Le1 HF (2007) Microwave irradiation: a novel method for rapid synthesis of D,L-lactide. Macromol Rapid Commun 28:417-421 